\title{
PENERAPAN MODEL PEMBELAJARAN PROCESS ORIENTED GUIDED INQUIRY LEARNING (POGIL) TERHADAP KEMAMPUAN PEMAHAMAN KONSEP DITINJAU DARI SELF-EFFICACY SISWA KELAS VIII SMP NEGERI 2 COMAL
}

\author{
Puput Rakhmawati \\ Program Studi Pendidikan Matematika \\ Fakultas Keguruan dan Ilmu Pendidikan \\ Universitas Pekalongan \\ Puputrakhmawati@gmail.com
}

\begin{abstract}
Abstrak
Penelitian ini bertujuan untuk mengetahui: (1) untuk mengetahui kemampuan pemahaman konsep matematika siswa yang menggunakan model pembelajaran POGIL lebih baik daripada kemampuan pemahaman konsep siswa yang diajar menggunakan pembelajaran Ekspositori, (2) untuk mengetahui kemampuan pemahaman konsep siswa dengan self-efficacy tinggi lebih baik daripada siswa dengan self-efficacy sedang dan rendah, (3) Untuk mengetahui siswa dengan self-efficacy tinggi, apakah kemampuan pemahaman konsep siswa yang menggunakan POGIL lebih baik daripada yang menggunakan model pembelajaran Ekspositori, kemampuan pemahaman konsep matematika siswa dengan self - efficacy sedang yang menggunakan model POGIL lebih baik daripada yang menggunakan model pembelajaran Ekspositori, dan kemampuan pemahaman konsep matematika siswa dengan self - efficacy rendah yang menggunakan POGIL lebih baik daripada menggunakan model pembelajaran Ekspositori.
\end{abstract}

Kata Kunci : Process Oriented Guided Inquiry Learning (POGIL), Kemampuan Pemahaman Konsep Matematis, Self-Efficacy.

\begin{abstract}
The aims of this research are: (1) to find out whether the students' ability to understand mathematic concept using POGIL method is better than the ability of studentswith expository learning, (2) to perceive whether the conceptual understanding of students with high self-efficacy is better than the students with medium and low self-efficacy, (3) to find out if the high self-efficacy students' mathematic conceptual understanding ability is better by applying POGIL than expository method, if the medium self-efficacy students' mathematic conceptual understanding ability is better by applying POGIL than expository method and if the low selfefficacy students' mathematic conceptual understanding ability is better by applying POGIL than expository method.
\end{abstract}

Keywords: Process Oriented Guided Inquiry Learning (POGIL), Ability of Mathematic Conceptual Understanding, Self-Efficacy.

\section{Pendahuluan}

Belajar adalah suatu proses usaha yang dilakukan seseorang untuk memperoleh suatu perubahan tingkah laku yang baru secara keseluruhan, sebagai hasil pengalamannya sendiri dalam interaksi dengan lingkungannya. Perubahan yang diperoleh seseorang setelah melalui sesuatu proses belajar meliputi perubahan keseluruhan tingkah lakunya. Jika seorang belajar 
sesuatu, sebagai hasilnya ia akan mengalami perubahan tingkah laku secara menyeluruh dalam sikap, keterampilan, pengetahuan dan sebagainya (Slameto, $2010: 2-4$ ).

Pembelajaran adalah suatu proses dimana siswa membina ide baru atau konsep berdasarkan kepada pengetahuan yang mereka miliki. Keterampilan dan pengetahuan yang didapatkan siswa diharapkan bukan dari hasil mengingat seperangkat fakta-fakta tetapi merupakan hasil dari penemuman sendiri (Suherman, 2003 : 214). Kegiatan penemuan konsep dapat dilakukan siswa melalui interaksi dengan guru atau peserta didik lain, kegiatan ini terdapat dalam model pembelajaran Process Oriented Guided Inquiry Learning (POGIL). Salah satu mata pelajaran yang dapat diterapkan dengan metode POGIL adalah matematika.

Matematika adalah mata pelajaran yang diberikan untuk dipelajari siswa di sekolah (formal), yaitu siswa SD/MI, SLTP/MTs, SLTA/SMK/MA. Matematika perlu diberikan kepada siswa untuk membekali kemampuan berfikir logis, analitis, sistematis, kritis, kreatif dan kemampuan bekerja sama. Matematika merupakan salah satu materi yang berkaitan dengan mempelajari ide-ide atau konsep yang bersifat abstrak. Hal ini membuat siswa beranggapan bahwa matematika merupakan mata pelajaran yang sulit. Pada kenyataannya banyak peserta didik yang kurang penguasaan terhadap konsep-konsep dalam matematika. Selain pemahaman konsep dalam matematika, penanaman konsep yang benar juga sangat diperlukan dalam kegiatan pembelajaran matematika. Jika konsep dasar yang diterima siswa salah, maka sukar memperbaiki kembali terutama jika sudah diterapkan dalam penyelesaian suatu permasalahan. Oleh karena itu, guru diharapkan mampu menciptakan berbagai kegiatan dan metode yang mampu membantu siswa dalam memahami konsep dengan benar, serta siswa mampu memecahkan suatu permasalahan dengan benar.

Self-efficacy dapat berupa bagaimana perasaan seseorang, cara berfikir, motivasi diri, dan keinginan diri terhadap sesuatu. Keyakinan tersebut menghasilkan efek yang beragam melalui empat proses utama, yaitu kognitif, motivasi, afektif, dan proses seleksi Bandura, (1993) dalam Sukanto dan Siregar, Y. A. (2017). Hal tersebut adalah salah satu yang perlu diperhatikan dalam pembelajaran, namun pada kenyataannya sikap ini belum seperti apa yang diharapkan. Karena disini siswa hanya cenderung bekerja, misalnya menyelesaikan soal apabila tidak jauh berbeda dengan contoh. Bahkan apabila diberikan soal yang sedikit berbeda mereka tidak mau berpikir keras untuk menyelesaikannya. Selain itu tidak sedikit siswa yang kurang peduli dan kurang bersemangat serta ragu dengan kemampuan yang ia miliki. Hal ini menjadi permasalahan dalam pembelajaran di SMP Negeri 2 Comal.

Pemilihan model pembelajaran yang tepat dalam proses pembelajaran matematika akan berpengaruh terhadap self-efficacy dan kemampuan pemahaman konsep siswa dalam memahami suatu konsep matematika. Salah satu model pembelajaran yang berpusat pada 
siswa aktif berinteraksi dengan teman sebaya adalah Process Oriented Guided Inquiry Learning (POGIL). POGIL adalah model pembelajaran yang didesain dengan kelompok kecil yang berinteraksi dengan instruktur / guru sebagai fasilitator. Model pembelajaran ini membimbing peserta didik melalui kegiatan eksplorasi agar peserta didik membangun pemahaman sendiri. POGIL diartikan sebagai pembelajaran dengan proses interaksi dengan berpikir secara hati-hati, mendiskusikan ide, mencerahkan pemahaman, melatih kemampuan, mencerminkan kemajuan, dan mengevaluasinya (Hanson, 2006) dalam Rosidah (2013).

Salah satu materi dalam pelajaran matematika kelas VIII semester I adalah pola bilangan. Materi pola bilangan sudah dibahas di sekolah dasar, jika siswa sudah ada gambaran tentang materi tersebut diharapkan siswa sudah menguasai materi pola bilangan dan diharapkan nilai yang bagus. Akan tetapi siswa masih kurang mampu mengingat pengertian dan contoh dari pola bilangan.

Berdasarkan wawancara didapat informasi dari guru matematika di SMP Negeri 2 Comal, didapati banyak siswa yang melakukan kesalahan dalam menyelesaikan soal matematika materi pola bilangan. Banyak siswa yang merasa kesulitan dalam memahami soal pola bilangan, sehingga hanya beberapa siswa yang dapat menyelesaikan soal pola bilangan dengan benar. Selebihnya tidak memahami, bahkan ada kecenderungan menghafal rumus yang ada di buku. Dalam proses pembelajaran matematika yang berlangsung guru menggunakan model ekspositori. Pada model pembelajaran ekspositori dapat membangun pemahaman konsep siswa, dimana siswa belajar lebih aktif mengerjakan latihan soal sendiri, saling bertanya maupun mengerjakan soal bersama dengan temannya dan menulis pekerjaannya dipapan tulis (Suherman dkk, 2003: 203).

Akan tetapi, penggunaan model ekspositori yang dilaksanakan pada kelas VIII di SMP Negeri 2 Comal belum maksimal dalam meningkatkan kemampuan pemahaman konsep siswa. Kebanyakan siswa belum memiliki kemampuan dalam menyatakan ulang suatu konsep, mengklasifikasikan objek-objek menurut sifat-sifat tertentu (sesuai dengan konsepnya), memberi contoh dan non contoh dari konsep yang dipelajari, menyajikan konsep dalam berbagai bentuk representasi matematika, dan mengaplikasikan konsep kedalam pemecahan masalah. Hal tersebut menunjukkan masih rendahnya kemampuan pemahaman konsep matematika siswa.

Hasil observasi dikelas, lebih dari 50\% siswa masih pasif dalam proses pembelajaran. Siswa sangat bergantung pada penjelasan dari guru, terlihat dari siswa cenderung hanya menerima informasi dari guru dan mencatat apa yang telah diberikan guru. Dalam proses berdiskusi masih dijumpai siswa yang belum aktif dan guru masih bertindak sebagai pusat kegiatan dan pemberi informasi, ketika ditunjuk mengerjakan soal di depan kelas siswa 
kurang percaya diri. Selain itu, siswa kurang aktif mencari solusi untuk permasalahannya. Siswa malu bertanya pada saat mengalami kesulitan dalam menyelesaikan soal karena seringkali lupa dengan rumus-rumus dasarnya.

Berdasarkan uraian di atas, peneliti menerapkan model pembelajaran POGIL dapat menjadi solusi atas permasalahan dalam materi pola bilangan yang terjadi di SMP Negeri 2 Comal. Pembelajaran dilihat dari self-efficacy yang tinggi dapat menumbuhkan dan menguatkan pemahaman konsep siswa. Maka peneliti bermaksud mengadakan penelitian yang berjudul "Penerapan Model Pembelajaran POGIL Terhadap Kemampuan Pemahaman Konsep Ditinjau dari Self-Efficacy Siswa Kelas VII SMP Negeri 2 Comal".

Tahap-tahap pembelajaran POGIL meliputi beberapa langkah, yaitu: (1) orientasi, (2) eksplorasi, (3) pembentukan konsep, (4) aplikasi, dan (5) kesimpulan. Langkah pembelajaran tersebut tentunya dapat melatih kemampuan pemahaman konsep siswa karena adanya kegiatan eksplorasi, pembentukan konsep dan penerapan dalam satu kelompoknya maupun ketika bereksplorasi dengan kelompok lain.

Tujuan dari penelitian ini adalah: (1) Untuk mengetahui apakah kemampuan pemahaman konsep matematika siswa yang menggunakan model pembelajaran POGIL lebih baik daripada kemampuan pemahaman konsep siswa yang diajar menggunakan pembelajaran Ekspositori, (2) Untuk mengetahui apakah kemampuan pemahaman konsep matematika siswa dengan Self - efficacy tinggi lebih baik daripada siswa dengan Self - efficacy sedang dan rendah (3) Untuk mengetahui apakah siswa dengan Self-efficacy tinggi, apakah kemampuan pemahaman konsep matematika siswa yang menggunakan POGIL lebih baik daripada yang menggunakan model pembelajaran Ekspositori, apakah kemampuan pemahaman konsep matematika siswa dengan Self-efficacy sedang yang menggunakan model POGIL lebih baik daripada yang menggunakan model pembelajaran Ekspositori, dan apakah kemampuan pemahaman konsep matematika siswa dengan Self - efficacy rendah yang menggunakan POGIL sama baiknya dengan yang menggunakan model pembelajaran Ekspositori?

\section{Metode Penelitian}

Jenis penelitian ini merupakan jenis penelitian eksperimental. Penelitian ini dilakukan di kelas VIII SMP Negeri 2 Comal tahun ajaran 2018/2019 dengan materi pola bilangan. Pengambilan sampel dilakukan dengan teknik cluster random sampling dan diperoleh kelas VIII A sebagai kelas eksperimen yang diberi pembelajaran dengan model pembelajaran POGIL serta diperoleh kelas VII B sebagai kelas kontrol yang diberi pembelajaran dengan pembelajaran ekspositori. 
Metode penelitian yang digunakan adalah metode kuantitatif. Teknik pengambilan data yang digunakan dalam penelitian ini adalah tes dan angket. Tes untuk mengukur tingkat kemampuan pemahaman konsep siswa dan angket untuk mengukur tingkat self-efficacy siswa.

Untuk menguji hipotesis digunakan analisis variansi (anava) dua jalan. Sebelum melakukan uji anava dua jalan, peneliti melakukan uji prasyarat berupa uji normalitas, uji homogenitas, dan uji kesamaan dua rata-rata dengan menggunakan data nilai ulangan akhir semester II kelas VII serta uji prasyarat anava berupa uji normalitas dan uji homogenitas dengan menggunakan data nilai tes kemampuan pemahaman konsep siswa.

\section{Hasil dan Pembahasan}

Penelitian ini diawali dengan analisis data awal. Analisis data awal dilakukan sebelum kelas eksperimen diberikan perlakuan. Analisis data awal dilakukan dengan uji normalitas, uji homogenitas, dan kesamaan rata-rata. Data yang digunakan berupa nilai ulangan akhir semester II siswa kelas VII SMP Negeri 2 Comal tahun ajaran 2018/2019.

Tabel 3.1. Hasil Uji Normalitas

Data Awal

\begin{tabular}{cccc}
\hline Kelas & L $_{\text {obs }}$ & $\mathbf{L}_{\text {tabel }}$ & Keterangan \\
\hline Eksperimen & 0,143 & 0,1566 & $\mathrm{H}_{0}$ diterima \\
\hline Kontrol & 0,147 & 0,1566 & $\mathrm{H}_{0}$ diterima \\
\hline
\end{tabular}

Hasil analisis uji normalitas dengan metode Liliefors menunjukkan bahwa $\mathrm{H}_{0}$ diterima sehingga berarti bahwa kedua sampel berdistribusi normal. Hasil analisis uji homogenitas dengan uji $\mathrm{F}$ untuk kelas eksperimen dan kontrol dengan taraf signifikansi 5\% diperoleh $\mathrm{F}_{\mathrm{obs}}=$ 1,071 dan $\mathrm{F}_{\text {tabel }}=1,822$, hal itu menunjukkan bahwa $\mathrm{H}_{0}$ diterima karena $\mathrm{F}_{\text {obs }}<\mathrm{F}_{\text {tabel }}$, maka disimpulkan bahwa kedua sampel berasal dari populasi yang memiliki variansi yang sama. Sedangkan untuk uji kesamaan rata-rata digunakan uji t dengan taraf signifikansi 5\%, diperoleh $t_{\text {hitung }}=0,452$ dan $t_{\text {tabel }}=1,999$, maka $\mathrm{H}_{0}$ diterima karena $-t_{\text {tabel }}<t_{\text {hitung }}<t_{\text {tabel }}$ disimpulkan bahwa rata-rata nilai siswa kelas eksperimen sama dengan rata-rata nilai siswa kelas kontrol.

Data awal yang dianalisis sudah normal, homogen, dan tidak ada perbedaan rata-rata dari kedua kelas sampel, selanjutnya diberikan perlakuan dengan model POGIL pada kelas eksperimen, dan pembelajaran ekspositori pada kelas kontrol. Selanjutnya dilakukan tes kemampuan pemahaman konsep dan dilakukan analisis data akhir.

Uji normalitas data akhir dibagi dalam lima kelompok untuk melihat normalitas data dari tiap model pembelajaran dan tingkat self-efficacy. Pengujian normalitas pada data akhir menggunakan metode Lilliefors dengan taraf signifikansi 5\% pengambilan keputusan jika diperoleh nilai $\mathrm{L}_{\mathrm{obs}}<\mathrm{L}_{\text {tabel }}$ maka data tersebut normal. 


\begin{tabular}{|c|c|c|c|}
\hline \multicolumn{4}{|c|}{ Data Akhir } \\
\hline $\begin{array}{l}\text { Sumber } \\
\text { Variansi } \\
\end{array}$ & Lobs & $\mathbf{L}_{\text {tabel }}$ & Keputusan \\
\hline \multicolumn{4}{|c|}{ Kemampuan Pemahaman konsep } \\
\hline Eksperimen & 0,071 & 0,157 & \multirow{3}{*}{$\mathrm{L}_{\mathrm{obs}}<\mathrm{L}_{\text {tabel }}$} \\
\hline Kontrol & 0,104 & 0,157 & \\
\hline \multicolumn{3}{|c|}{ Tingkat Minat } & \\
\hline Tinggi & 0,082 & 0,181 & \\
\hline Sedang & 0,065 & 0,185 & $\mathrm{~L}_{\mathrm{obs}}<\mathrm{L}_{\text {tabel }}$ \\
\hline Rendah & 0,151 & 0,215 & \\
\hline
\end{tabular}

Hasil analisis uji normalitas dengan metode Liliefors menunjukkan bahwa kedua sampel berdistribusi normal. Uji homogenitas pada data akhir dilakukan dua kali, yaitu homogenitas antar kelas dan homogenitas antar kategori self-efficacy. Untuk menguji homogenitas antar kelas menggunakan prosedur yang sama dengan homogenitas data awal yaitu uji F, sedangkan untuk homogenitas antar kategori minat digunakan metode Bartlett.

\begin{tabular}{lccc} 
Tabel 3.3. Hasil Analisis Uji Homogenitas Data Akhir \\
\hline Kelompok & Fobs $_{\text {obs }}$ & F $_{\text {tabel }}$ & Keputusan \\
\hline $\begin{array}{l}\text { Model } \\
\text { pembelajaran }\end{array}$ & 1,073 & 1,822 & $\mathrm{H}_{0}$ diterima \\
Tingkat Self - & $\mathbf{b}_{\text {obs }}$ & b tabel & \\
efficacy & 0,99 & 0,90 & $\mathrm{H}_{0}$ diterima \\
\hline
\end{tabular}

Hasil uji homogenitas data akhir terlihat bahwa $\mathrm{H}_{0}$ diterima maka disimpulkan sampel dari masing-masing kelompok yaitu kelompok model pembelajaran dan tingkat self - efficacy adalah homogen.

Metode statistik yang digunakan dalam penelitian ini adalah uji anava dua jalan sel tak sama. Tujuan analisis variansi pada penelitian ini adalah untuk menguji signifikansi efek dua variabel bebas (model pembelajaran dan self - efficacy) terhadap satu variabel terikat (kemampuan pemahaman konsep matematika). Dari perhitungan uji anava dua jalan diperoleh $\mathrm{F}(\mathrm{A})_{\mathrm{obs}}=4,371>\mathrm{F}_{\text {tabel }}=4,007$ maka $\mathrm{H}_{0 \mathrm{~A}}$ ditolak, $\mathrm{F}(\mathrm{B})_{\mathrm{obs}}=3,796>\mathrm{F}_{\text {tabel }}=3,156$ maka $\mathrm{H}_{0 \mathrm{~B}}$ ditolak, dan $\mathrm{F}(\mathrm{AB})_{\mathrm{obs}}=0,0073<\mathrm{F}_{\text {tabel }}=3,156$ maka $\mathrm{H}_{0 \mathrm{AB}}$ diterima. Hal tersebut berarti: (1) terdapat perbedaan kemampuan pemahaman konsep antara siswa yang memperoleh pembelajaran POGIL dengan siswa yang memperoleh pembelajaran ekspsitori, (2) terdapat perbedaan kemampuan pemahaman konsep antara siswa yang mempunyai self-efficacy siswa tinggi dengan siswa yang mempunyai self-efficacy siswa sedang atau rendah, (3) tidak terdapat interaksi antara model pembelajaran dan tingkat self-efficacy siswa terhadap kemampuan pemahaman konsep matematika siswa.

Dari perhitungan analisis variansi di atas diperoleh bahwa $\mathrm{H}_{0 \mathrm{~A}}$ ditolak dan $\mathrm{H}_{0 \mathrm{~B}}$ ditolak, maka perlu dilakukan uji komparasi ganda atau uji lanjut pasca anava dengan metode Scheffee.

Tabel 3.4. Rerata dan Rataan Marginal Kemampuan Pemahaman Konsep 


\begin{tabular}{lcccc}
\hline & \multicolumn{3}{c}{ Tingkat self-efficacy } & Rerata \\
\cline { 2 - 4 } & Tinggi & Sedang & Rendah & Marginal \\
\hline POGIL & 78.385 & 75.833 & 65.857 & 73.358 \\
ekspositoriri & 70.545 & 67.182 & 58.300 & 65.342 \\
Rerata Marginal & 90.385 & 87.333 & 74.357 & \\
\hline
\end{tabular}

Berdasarkan tabel diatas, bahwa rerata model POGIL yaitu 73,358 lebih tinggi daripada rerata pembelajaran ekspositori yaitu 65,342. Dapat disimpulkan bahwa kemampuan pemahaman konsep siswa dalam pembelajaran POGIL lebih baik dibandingkan dengan pembelajaran ekspositori. Sejalan dengan penelitian Rosidah (2013) memperoleh bahwa pembelajaran dengan menggunakan model pembelajaran POGIL lebih tinggi daripada ratarata kemampuan siswa yang diajar dengan model pembelajaran ekspositori.

\section{Tabel 3.5. Hasil Uji Komparasi Ganda Antar Kolom}

\begin{tabular}{cccc}
\hline Interaksi & $\mathrm{F}_{\mathrm{obs}}$ & $\mathrm{F}_{\text {tabel }}$ & Keputusan \\
\hline$\mu_{1}=\mu_{2}$ & 0,484 & 6,3118 & $\mathrm{H}_{0}$ diterima \\
$\mu_{2}=\mu_{3}$ & 7,277 & 6,3118 & $\mathrm{H}_{0}$ ditolak \\
$\mu_{1}=\mu_{3}$ & 11,303 & 6,3118 & $\mathrm{H}_{0}$ ditolak \\
\hline
\end{tabular}

Dari tabel uji komparasi rerata antar kolom diatas, maka diperoleh hasil sebagai berikut: (1) kemampuan pemahaman konsep siswa yang memiliki self-efficacy tinggi sama baik dengan siswa yang memiliki self-efficacy sedang, (2) siswa yang memiliki self-efficacy sedang mempunyai kemampuan pemahaman konsep yang lebih baik daripada siswa yang memiliki self-efficacy rendah, (3) siswa yang memiliki self-efficacy tinggi mempunyai kemampuan pemahaman konsep yang lebih baik daripada siswa yang memiliki self-efficacy rendah.

Dilihat dari rerata marginal pada tabel 3.4 untuk model pembelajaran POGIL $\bar{X}_{2}=75,833<\bar{X}_{1}=78,385>\bar{X}_{3}=65,857$, sedangkan pada pembelajaran ekspositori $\bar{X}_{1}=70,545>\bar{X}_{2}=67,182<\bar{X}_{3}=58,300$ Hal tersebut berarti bahwa siswa dengan menggunakan model POGIL kemampuan pemahaman konsep siswa yang memiliki selfefficacy tinggi lebih baik daripada self-efficacy sedang maupun rendah. Pada pembelajaran ekspositori kemampuan pemahaman konsep siswa yang mempunyai self-efficacy tinggi lebih baik daripada self-efficacy sedang dan rendah. Namun, kemampuan pemahaman konsep siswa yang mempunyai self-efficacy rendah lebih baik daripada self-efficacy sedang.

Siswa dengan self-efficacy matematika tinggi cenderung menyukai matematika dan tertarik pada masalah nyata yang ditampilkan dalam pembelajaran POGIL dan pembelajaran ekspositori. Siswa berupaya menemukan pemahaman konsep dengan menggali pengetahuan yang telah siswa miliki maupun informasi dari berbagai sumber. Apalagi bila siswa bekerja dalam kelompok, proses penyelesaian masalah menjadi lebih menarik. Ketika menjumpai 
hambatan, siswa dengan self-efficacy tinggi akan berupaya mengatasinya dengan berbagai cara.

Siswa dengan self-efficacy sedang dan rendah, tidak begitu menyukai matematika dan tidak pula membencinya. Pada kondisi ini siswa akan mempunyai dua kecenderungan, sebagian akan bisa menjadi tertarik pada masalah nyata yang disajikan dalam pembelajaran dan sebagian yang lain menjadi kurang termotivasi ketika menghadapi masalah matematika. Ketika siswa menjadi termotivasi dan melibatkan diri dalam upaya pemahaman konsep, siswa akan belajar sama baiknya dengan siswa yang memiliki self-efficacy tinggi menjadikan hasil belajarnya menjadi optimal.

\section{Kesimpulan}

1. Berdasarkan hasil penelitian dan pembahasan yang telah diuraikan sebelumnya, maka dapat disimpulkan bahwa: (Kemampuan pemahaman konsep matematika siswa yang menggunakan model pembelajaran POGIL lebih baik daripada kemampuan pemahaman konsep siswa yang diajar menggunakan pembelajaran Ekspositori.

2. Kemampuan pemahaman konsep matematika siswa yang memiliki tingkat self - efficacy tinggi sama baiknya dengan siswa yang memiliki tingkat self-efficacy sedang, kemampuan pemahaman konsep matematika siswa yang memiliki tingkat self - efficacy sedang lebihbaik daripada siswa dengan tingkat self - efficacy rendah dan kemampuan pemahaman konsep matematika siswa yang memiliki tingkat self - efficacy tinggi lebihbaik daripada siswa dengan tingkat self-efficacy rendah.

3. Tidak terdapat efek antara model pembelajaran dan self - efficacy siswa terhadap kemampuan pemahaman konsep matematika dimana siswa yang mengikuti pembelajaran POGIL mempunyai kemampuan pemahaman konsep matematika yang lebih baik daripada siswa yang mengikuti pembelajaran ekspositori baik untuk siswa dengan self - efficacy tinggi, sedang maupun rendah.

\section{Pustaka}

Budiyono. 2009. Statistika untuk Penelitian. EdisiKedua. Surakarta: UNS Press.

Rosidah. 2013. "Keefektifan Pembelajaran POGIL berbantuan LKPD Terhadap Kemampuan Pemecan Masalah Materi Pokok Peluang”. Jurnal Kreano. 4, (1), 74.

Slameto. 2010. Belajar dan Faktor-Faktor yang Mempengaruhinya. Jakarta: Rineka Cipta.

Suherman, E. dkk. 2003. Strategi Pembelajaran Matematika Kontemporer. Bandung: UPI JICA. 
Sukanto dan Siregar, Y. A. 2017. "Hubungan Self-Efficacy dan Sikap Positif Terhadap Prestasi Akademik Siswa SMK Negeri 1 Sipirok". MES Journal of Education and Science. 3, (1). 
